$5-1-2020$

\title{
Guatemala: COVID-19 knowledge, attitudes and practices-Perspectives from 144 key informants in 10 indigenous municipalities
}

Population Council

Follow this and additional works at: https://knowledgecommons.popcouncil.org/departments_sbsr-pgy

Part of the International Public Health Commons, and the Social and Behavioral Sciences Commons How does access to this work benefit you? Let us know!

\section{Recommended Citation}

"Guatemala: COVID-19 knowledge, attitudes and practices-Perspectives from 144 key informants in 10 indigenous municipalities," COVID-19 Research \& Evaluations brief. Guatemala: Population Council, 2020. 


\section{Guatemala: COVID-19 Knowledge, Attitudes \& Practices}

\section{Perspectives from 144 key informants in 10 indigenous municipalities}

April 14-18, 2020

\section{Highlights}

- $100 \%$ of respondents are aware of COVID-19, and $74 \%$ know that anyone can get infected.

- Knowledge of at-risk groups and major symptoms are high. However, more than half incorrectly identified children as particularly at risk and there was lower awareness of difficulty breathing and fatigue as symptoms.

- Frontline health workers and municipal officers had the highest perceived risk of being infected with COVID-19, while community leaders, heads of household, and young indigenous women who are former adolescent girl group mentors had the lowest perceived risk. Teachers fell in the middle.

- Respondents stated that TV programs, followed by the President's announcements and TV advertisements were the most trusted sources of COVID-19 information-a majority get information from TV and radio shows.

- There is mixed knowledge on measures to prevent infection-more awareness on handwashing and masks, compared to social distancing. Indigenous community members may face challenges in adhering to promoted sanitation and hygiene and social distancing guidelines due to a lack of personal water sources, the expense of hand sanitizer, and single-room households.

- Key informants are most worried about infecting other people, followed by COVID-19's potential deadly impact and its impact on livelihoods.

\section{Key Informant Interviews}

The Population Council has a longstanding partnership with indigenous communities through the Abriendo Oportunidades (AO) program. Our experience working in indigenous settings has allowed us to witness a lack of indigenous inclusion in government activities. To better understand indigenous knowledge, perspectives, and needs related to the COVID-19 pandemic in Guatemala, we conducted 144 key informant interviews using mobile phones in 10 municipalities on April 14-18, 2020.
Guatemala:

585 cases 16 deaths

As of April 30, 2020. Source: Johns Hopkins Coronavirus Resource Center.

Respondents were $72 \%$ female, and the average age was 38 years (range: 18-70). The average household size among respondents was 6 people, and more than half had completed at least secondary school. Informants were comprised of: frontline health workers (25\%), heads of household (23\%), young indigenous women/former girl program mentors (16\%), community leaders $(15 \%)$, municipal officers $(12 \%)$, and teachers $(9 \%)$. 


\section{Knowledge on Infection, Symptoms, and Prevention Measures}

- All (100\%) had heard of COVID-19; 74\% knew that everyone can become infected.

- 9 out of 10 indicated that the elderly were at high risk and only 4 out of 10 correctly identified immunocompromised individuals as an at-risk population. 57\% incorrectly identified children as being at high risk for severe illness, especially among teachers and heads of household. Frontline health workers and teachers mentioned that deportees could be at high risk, which may be a predictor of stigma against returned immigrants.

- 9 in 10 respondents knew that fever is a symptom of coronavirus, and 8 in 10 knew that dry cough also presents in coronavirus cases. Only $48 \%$ knew that difficulty breathing was a symptom, which may pose a concern as this is a severe symptom and access to hospitalization is limited to distant health centers. Overall knowledge of symptoms was highest among frontline health workers and municipal officers.

- 9 in 10 respondents would go to a clinic or go for a coronavirus test if they started exhibiting symptoms, which coincides with the government guidance on what to do if people become ill.

- $\quad$ There is mixed knowledge on measures to prevent infection, as 8 in 10 respondents would wash hands more frequently and wear masks, $53 \%$ would stay home, $30 \%$ would keep a distance of at least 2 meters, and 29\% would stop attending social gatherings.

- Respondents cited TV shows (37\%), followed by the President's announcements (35\%) and TV advertisements (25\%) as the most reliable sources of information on COVID-19. News-seeking behavior has increased over the past month for 8 out of 10 respondents.

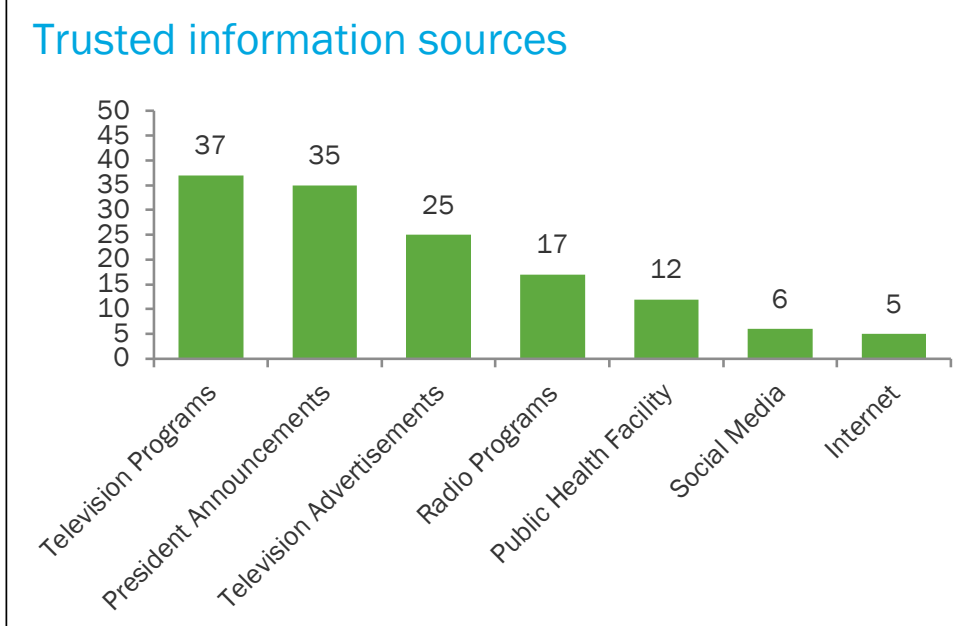

\section{Risk Perception}

Risk perceptions varied by different groups of key informants. Respondents who were unable to practice certain social distancing behaviors were also likely to report being at higher risk.

- Overall, $46 \%$ of respondents said they were at high risk of becoming infected; frontline health workers were the most likely to say they were at high risk (67\%), while community leaders were least likely to say they were at high risk (27\%).

- Frontline health workers (67\%) and municipal officers (57\%) reported being at high risk. These respondents also were less likely, compared to other informants, to report staying at home more during the past month.

- Young indigenous women (38\%) were more likely to say they were at low risk of infection which may be because they think their communities are far from urban areas.

- 9 in 10 would be very concerned if they or someone in their household became infected.

- 8 in 10 said that adoption of social distancing measures meant that they were at low risk of infection. 


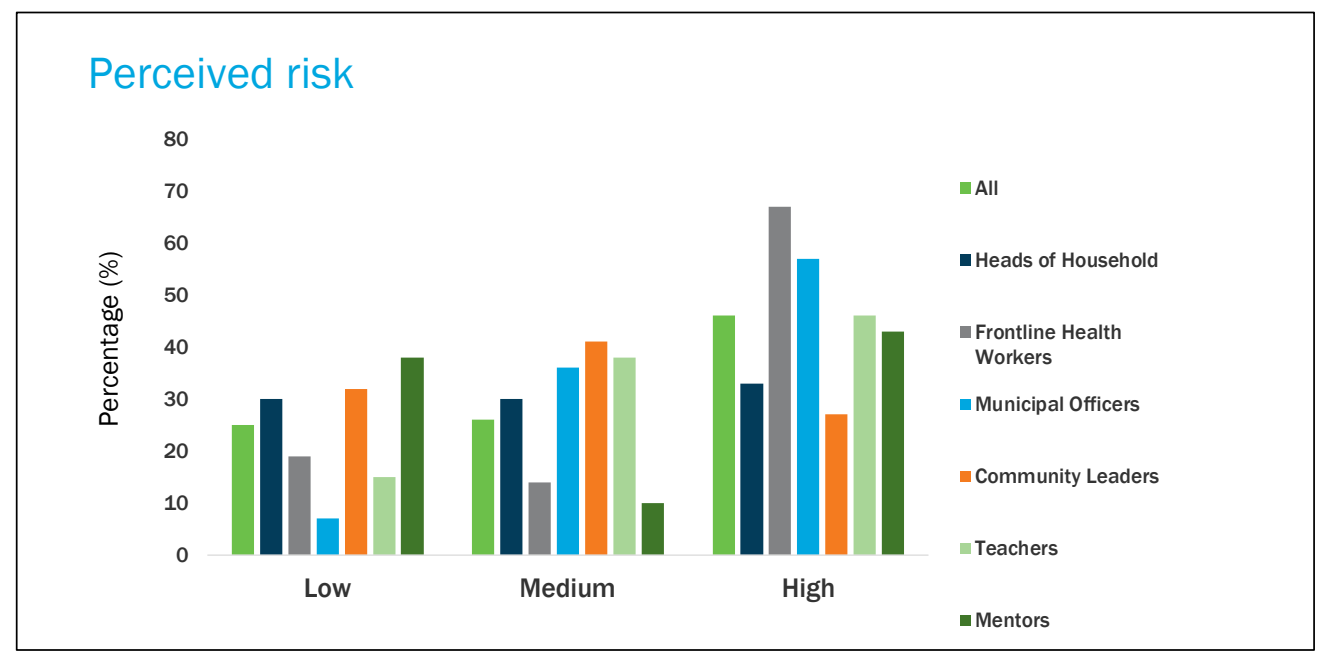

\section{Challenges to Community Prevention}

At least 9 out of 10 participants reported already adopting at least one promoted COVID-19 prevention behavior (social distancing/self-isolation and handwashing). The main challenges identified were:

- About one-third of respondents do not have a separate room for isolating a sick person, and $38 \%$ are concerned that single-room households may make social distancing difficult.

- $56 \%$ think community members would stay home for 14 days if they were ordered to do so. Frontline health workers were the least confident in community members following a stay-at-home order.

- Proper handwashing hygiene may be difficult. Half said personal sources of water are lacking, and 4 in 10 respondents stated that community members may not be able to afford hand sanitizer.

\section{Concerns and Needs}

Participants expressed fears and concerns about COVID-19 regarding: 1) infecting others (51\%); 2) dying from the virus (42\%); and 3) economic fallout of the pandemic, including loss of income (32\%) and food shortages (14\%). In the case of an ongoing lockdown, participants expressed concern about access to food (98\%), followed by water $(30 \%)$ and basic services (20\%) such as electricity, housing, and waste removal.

\section{Subgroup Considerations}

- Community leaders (53\%)

\section{Critical needs for lockdown}

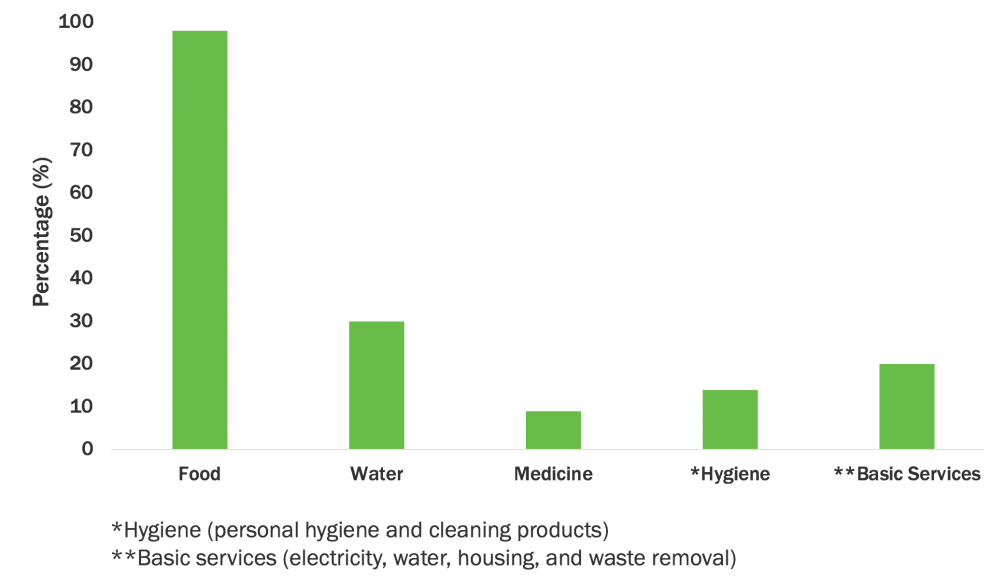

were most concerned about the economic effects of the pandemic, vis-a-vis loss of income, compared to other groups.

- Outreach to specific groups with provision of personal protective equipment may be needed. Frontline health workers have not been able to stay home more and were also the most likely to say that the 
government is not doing enough to stop the spread. Municipal workers were also less likely be able to stop attending social gatherings compared to the overall group.

- To follow a stay-at-home order, municipal officers (15\%) reported needing support for telecommunications with data/airtime bundles.

- Heads of households were most likely to need basic personal hygiene and cleaning products (25\%).

\section{Recommendations}

- The Government of Guatemala should intensify efforts to deliver accurate information on the prevention of COVID-19 to indigenous communities, with a focus on:

- Developing a COVID-19 road map for community action when a case is identified in a given municipality, facilitating alternatives to self-isolation given the impracticality of this method for the poorest households.

- Recommendations about what to do when severe symptoms like difficulty breathing show, considering that access to hospitalization is limited in indigenous communities.

- Conveying tailored, actionable information with a multilingual approach through TV and the President's announcements, which are a trusted source of information for these communities.

- Engaging community leaders, teachers, midwives, and young indigenous female mentors through text messages to deliver information at the community and household levels using digital methods while limiting physical contact. As reported in this study, $90 \%$ of these informants already own phones.

- Support frontline health workers and municipal officers who expressed they are at high risk and are not able to stay at home due to their profession by providing them with personal protective equipment.

- Central and municipal government should intensify efforts to address the impact of food insecurity and loss of income, and guarantee indigenous communities access to hygiene products and medicine.

This brief represents research in progress. Content has not been peer reviewed, and this version may be updated with additional analyses in subsequent publications. Contact: adelvalle@popcouncil.org 